\title{
О РОЛИ ПРЕДВАРИТЕЛЬНОЙ ОЧИСТКИ СУЛЬФИДА КАДМИЯ В ОБРАЗОВАНИИ ЛЮМИНОФОРОВ $\mathrm{CdS}-\mathrm{Ag}$
}

Экспериментальные данные разных исследователей, полученные по активации сульфида кадмия серебром, имеют большие расхождения. Максимумы оранжевых и красных полос свечения колеблются в пределах $580-650$ и $715-740$ нм соответственно [1-6]. Различны и данные о соотношении красных и оранжевых полос $\left[{ }^{4-6}\right]$, об оптимальных условиях легирования люминофоров серебром и влиянии стехиометрии. Так как в экспериментах используется исходный сульфид кадмия разного происхождения, а также разные методы его дополнительной очистки перед приготовлением люминофоров (применяются также исходные порошки промышленного производства без дополнительной очистки), вполне вероятно, что значительные расхождения в результатах объясняются наличием в люминофорах неконтролируемых примесей. По мнению авторов работы [7], присутствие неконтролируемых примесей может

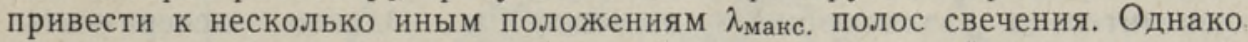
и другие расхождения могут быть обусловлены разной степенью чистоты используемых исходных материалов.

Мы попытались выяснить роль происхождения исходного материала и методов его очистки в возникновении разных результатов при легировании сульфида кадмия серебром и найти возможность устранения примесей, которые сильно изменяют результаты легирования.

\section{Экспериментальная часть}

В качестве исходных материалов использовали сульфид кадмия ч.д.л. и сульфид кадмия промышленного производства о.ч. (содержание серебра, меди, никеля и кобальта не выше $1 \cdot 10^{-5}$ вес.\%, алюминия, железа и магния не выше $2 \cdot 10^{-5}$ вес. \%). Очистку исходного материала проводили методом прокалки сульфида кадмия в потоке сероводорода, предложенным Гурвичем [4], или методом пересублимирования в вакууме $\left.{ }^{8}\right]$. Кроме использованных нами ранее методов очистки, в данной работе применяли новую модификацию метода очистки CdS пересублимированием в вакууме, степень которого была повышена до $10^{-5}$ мм pт. ст. Исходный порошок испарялся в вакууме при температуре $650^{\circ} \mathrm{C}$ и осаждался на поверхность с температурным градиентом. Использовали только более низкотемпературные фракции пересублимированного порошка, которые при температуре жидкого азота не люминесцировали. Для исключения возможности проникновения кислорода через стенку 
кварцевой трубы последняя изготовлялась с двойными стенками, между которыми пропускали поток аргона. Чтобы уменьшить вероятность попадания случайных примесей из кварца при высоких температурах, систему предварительно откачивали до высокого вакуума и затем прокаливали при постоянной откачке и температуре сублимации в течение 5 .

Люминофоры изготовляли в виде порошков прокалкой в потоке аргона. Серебро вводили в шихту в виде $\mathrm{Ag}_{2} \mathrm{~S}, \mathrm{AgNO}_{3}$ или $\mathrm{AgCl}$. При приготовлении некоторых люминофоров в качестве соактиватора использовали галлий $\left(\mathrm{Ga}_{2} \mathrm{~S}_{3}\right)$. В отличне от наших более ранних экспериментов [ $\left.{ }^{9}\right]$ в большинство люминофоров примеси вводили путем сухого перемешивания, а для аргона использовали ловушку с жидким азотом.

С целью изменения стехиометрического состава очищенного исходного материала $\mathrm{CdS}$ прокаливали в запаянных ампулах с повышенным давлением серы или кадмия. Методика измерений спектров люминесценции описана в [9]. Для выяснения влияния исходного материала и методов его очистки на свойства люминофоров были изготовлены в совершенно одинаковых условиях люминофоры $\mathrm{CdS}-\mathrm{Ag}_{2} \mathrm{~S}^{*}\left(10^{-2}\right.$ моль\%) и $\mathrm{CdS}-\mathrm{AgNO}_{3}\left(10^{-2}\right.$ моль \%) из очищенного разными методами сульфида кадмия ч.д.л. и о.ч. При этом оба исходных материала (о.ч. и ч.д.л.) после очистки как в потоке сероводорода, так и методом сублимации (степень вакуума $10^{-2}$ мм рт. ст.) имели только краевое свечение, и изменением одной лишь стехиометрии нельзя было вызвать появления более длинноволновых полос свечения. После очистки методом сублимации в высоком вакууме $\left(10^{-5}\right.$ мм рт. $c T$.) оба материала не имели свечения. Свечение не возникало также при изменении их стехиометрического состава. Так как отсутствуют точные критерии оценки чистоты исходных материалов, то обычно считается [ $\left.{ }^{4}\right]$, что названные порошки достаточно чисты от примесей, участвующих в создании центров свечения. Таким образом, можно ожидать, что при введении серебра в одинаковых условиях во всех случаях будут получены одинаковые или незначительно различающиеся люминофоры. Однако эксперименты показали (рис. $1, a)$, что свойства приготовленны сят от исходного материала и методов его очистки. Если исходные порошки ч.д.л. и о.ч. очищены в потоке сероводорода, то получаются

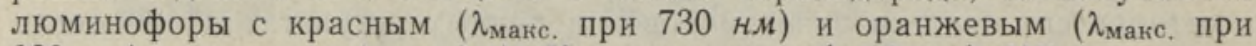
620 нм) свечением (рис. 1,a). Использование $\mathrm{Ag}_{2} \mathrm{~S}$ и $\mathrm{AgNO}_{3}$ для легирования серебром дает одинаковые результаты. Яркость свечения у этих люминофоров слабее, чем у люминофоров, при изготовлении которых использовались пересублимированные в вакууме материалы.

При очистке методом сублимации в низком вакууме (10-2 мм рт. ст.) после легирования серебром из обоих исходных порошков получаются люминофоры с ярким свечением, но с сильно различающимися максимумами излучения (при использовании исходного порошка ч.д. л. максимум свечения находится при $580 \mathrm{HM}$, при использовании порошка о. ч. - при $620 \mathrm{\mu м}$, и немного слабее при $740 \mathrm{mм})$. Таким образом, после очистки пересублимацией в низком вакууме индивидуальные особенности исходных материалов, которые, на наш взгляд, связаны с содержащимися в них примесями, сохраняются в бо́льшей мере, чем после очистки в потоке сероводорода. Упомянутые примеси играют, по-видимому, важную роль в процессе образования центров свечения. Смешанный порошок (50\% исходного о. ч. порошка и $50 \%$ ч. д. л. порошка) после пересублимирования в вакууме сразу после процесса очистки кроме краевого излучения имеет также оранжевую полосу (максимум свечения при 580 нм). После активации серебром краевое излучение исчезает, 

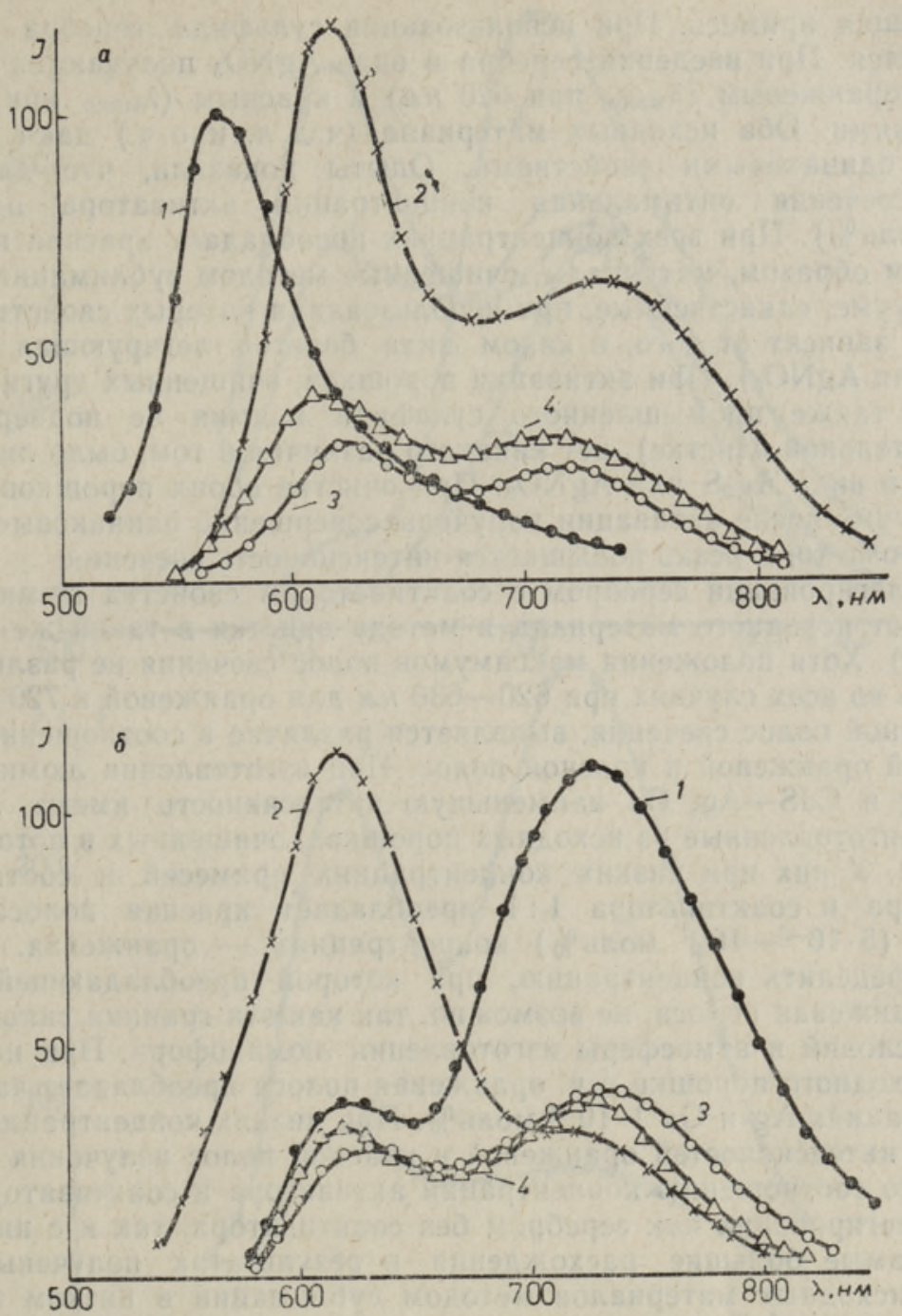

Рис. 1. Спектры свечения люминофоров, полученных из предварительно очищенного сульфида кадмия: $a-\mathrm{CdS}-\mathrm{Ag}_{2} \mathrm{~S}$ $\left(10^{-2}\right.$ моль $\left.\%\right), 6-\mathrm{CdS}-\mathrm{Ag}, \mathrm{Ga}\left(10^{-2}\right.$ моль \%); $1,3-$ исходный порошок ч.д.л., 2, 4 - исходный порошок о.ч. Сульфид кадмия очищен пересублимированием в вакууме при $10^{-2}$ мм рт. ст. $(1,2)$ и в потоке $\mathrm{H}_{2} \mathrm{~S}(3,4)$.

а полоса при 580 нм остается без изменений (не ослабляется и не усиливается). Следовательно, приписывать эту полосу примеси серебра представляется сомнительным. Примеси, входящие в состав центров

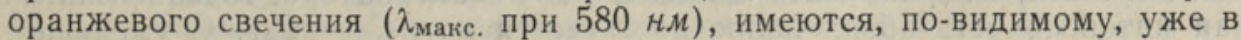
исходных материалах, и серебра для создания этих центров не требуется.

Результаты, полученные методом сублимации в высоком вакууме $\left(10^{-5}\right.$ мм рт. ст.), отличаются от результатов, полученных вышеописанным методом, прежде всего тем, что независимо от исходного материала, очищенный $\mathrm{CdS}$ не имеет никакого свечения. После легирования серебром в потоке аргона результат зависит от того, в каком виде вводится 
легирующая примесь. При использовании сульфида серебра порошок не светится. При введении серебра в виде $\mathrm{AgNO}_{3}$ получаются люмино-

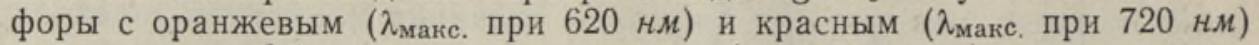
излучениями. Оба исходных материала (ч.д.л. и о.ч.) дают люминофоры с одинаковыми свойствами. Опыты показали, что для обеих полос свечения оптимальная концентрация активатора одинакова $\left(10^{-1}\right.$ моль\%). При всех концентрациях преобладает красная полоса.

Таким образом, материалы, очищенные методом сублимации в высоком вакууме, единственные, при использовании которых свойства люминофоров зависят от того, в каком виде берется легирующая примесь $\left(\mathrm{Ag}_{2} \mathrm{~S}\right.$ или $\left.\mathrm{AgNO}_{3}\right)$. При активации порошков, очищенных другими методами (а также промышленного сульфида кадмия не подверженного дополнительной очистке), нет никакого различия в том, было ли серебро введено в виде $\mathrm{Ag}_{2} \mathrm{~S}$ или $\mathrm{AgNO}_{3}$. При очистке обоих порошков в высоком вакууме после активации получены совершенно одинаковые результаты. Кроме того, резко повышается интенсивность свечения.

При легировании серебром с соактиватором свойства люминофоров зависят от исходного материала и метода очистки в такой же степени (рис. 1,6$)$. Хотя положения максимумов полос свечения не различаются, находясь во всех случаях при $620-630$ нм для оранжевой и $720-740$ нм для красной полос свечения, выявляется различие в соотношении интенсивностей оранжевой и красной полос. При изготовлении люминофоров $\mathrm{CdS}-\mathrm{Ag}$ и $\mathrm{CdS}-\mathrm{Ag}, \mathrm{Ga}$ наименьшую интенсивность имеют люминофоры, приготовленные из исходных порошков, очищенных в потоке сероводорода. У них при низких концентрациях примесей и соотношении активатора и соактиватора 1:1 преобладает красная полоса, а при высоких $\left(5 \cdot 10^{-2}-10^{-1}\right.$ моль \%) концентрациях - оранжевая. Однако, четко определить концентрацию, при которой преобладающей становится оранжевая полоса, не возможно, так как эта граница сильно зависит от условий и атмосферы изготовления люминофора. При использовании исходного порошка о. ч. оранжевая полоса преобладает часто при концентрациях $\mathrm{Ag}$ и $\mathrm{Ga} 1 \cdot 10^{-2}$ моль \%. При низких концентрациях соотношение интенсивностей оранжевой и красной полос излучения пропорционально соотношению концентраций активатора и соактиватора.

При легировании как серебром без соактиватора, так и с ними совместно самые большие расхождения в результатах получены после очистки исходных материалов методом сублимации в низком вакууме (10-2 м.м рт. ст.). Для исходного порошка о.ч., независимо от соотношения концентраций активатора и соактиватора, преобладающей остается

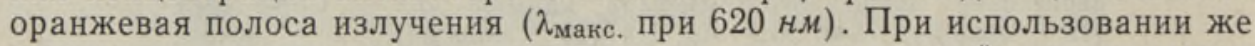
исходного порошка ч.д.л. соотношение интенсивностей оранжевых и красных полос излучения пропорционально соотношению концентраций активатора и соактиватора. Однако изменение этого соотношения не связано с простым перераспределением интенсивностей между оранжевой и красной полосами излучения, так как суммарная интенсивность свечения не остается постоянной. Если при фиксированной концентрации активатора варьировать концентрацию соактиватора, то максимальная интенсивность обеих полос достигается при $C_{\mathrm{Ga}}=C_{\mathrm{Ag}}$. C уменьшением концентрации соактиватора интенсивность оранжевой полосы уменьшается медленнее, а с увеличением - быстрее, чем интенсивность красной полосы.

Пересублимированные в высоком вакууме порошки дают самые яркие люминофоры $\mathrm{CdS}-\mathrm{Ag}, \mathrm{Ga}$ (интенсивность излучения на $1-2$ порядка выше, чем при $\mathrm{CdS}$, очищенном в потоке $\mathrm{H}_{2} \mathrm{~S}$ ), причем это не зависит от марки сульфида кадмия. Оказывается, что соотношение интенсивно- 


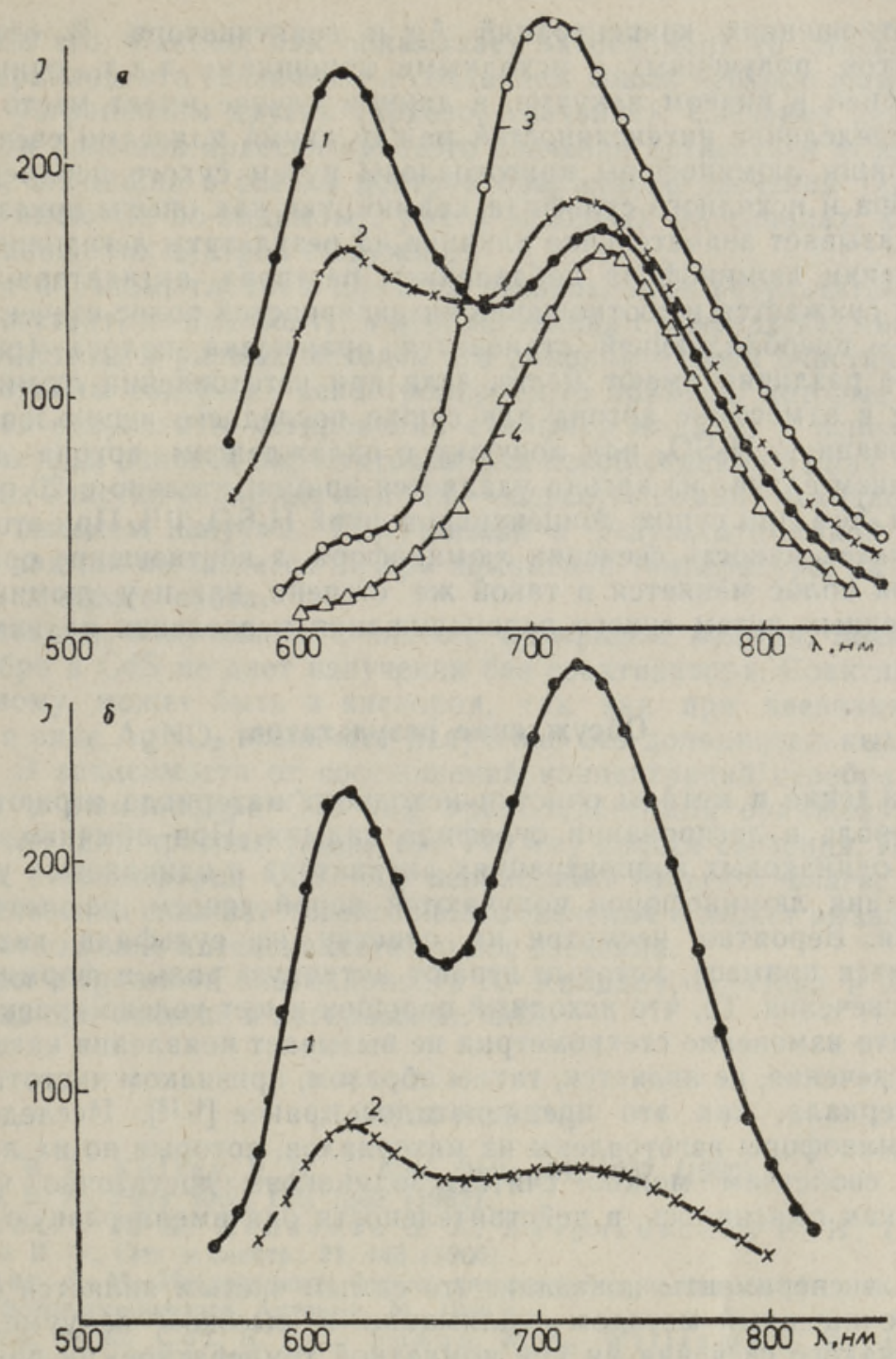

Рис. 2. $a-$ спектры свечения люминофоров $\mathrm{CdS}-\mathrm{Ag}, \mathrm{Ga}$ с различным соотношением концентраций $\mathrm{Ag}$ и $\mathrm{Ga}$, изготовленных из очнщенного пересублимированнем в вакууме при $10^{-5}$ м. $p T$. $\mathrm{CdS}: 1-\mathrm{Ag}\left(10^{-1}\right.$ моль $\left.\%\right), \mathrm{Ga}\left(10^{-2}\right.$ моль $\left.\%\right), 2-\mathrm{Ag}$ $\left(10^{-1}\right.$ моль $\left.\%\right), \mathrm{Ga}\left(4 \cdot 10^{-2}\right.$ моль $\left.\%\right), 3-\mathrm{Ag}\left(10^{-1}\right.$ моль $\left.\%\right), \mathrm{Ga}$ $\left(10^{-1}\right.$ моль $\left.\%\right), 4-\mathrm{Ag}\left(10^{-1}\right.$ моль $\left.\%\right), \mathrm{Ga}\left(5 \cdot 10^{-1}\right.$ моль $\left.\%\right)$. 6 - влияние условнй нзготовления на спектры свечения люминофоров CdS- $\mathrm{AgNO}_{3}\left(10^{-1}\right.$ моль\%): 1 - изготовлен путем сухого перемешнвания, 2 - активатор введен из раствора. Исходный материал очнщен пересублимированием в вакууме при $10^{-5}$ мм рт. ст.

стей оранжевой и красной полос свечения при всех концентрациях примесей $\left(10^{-4}-1\right.$ моль\%) пропорционально соотношенню концентраций активатора и соактиватора (рис. 2,a). Это согласуется с данными [10] и [ $\left.{ }^{4}\right]$, но в отличие от их результатов при такой степени чистоты исходного материала отсутствует предельная граница концентрации активатора, выше которой оранжевая полоса становится преобладающей при 
всех соотношениях концентраций Ag и соактиватора. В отличие от результатов, полученных с исходными порошками ч.д.л., очищенными сублимадией в низком вакууме, в данном случае имеет место простое перераспределение интенсивностей между двумя полосами свечения.

Все наши люминофоры приготовлены путем сухого перемешивания активатора и исходного сульфида кадмия, так как опыты показали, что влага оказывает значительное влияние на результаты легирования. При изготовлении люминофора добавлением раствора активатора яркость свечения снижается и соотношение интенсивностей полос свечения изменяется - преобладающей становится оранжевая полоса (рис. 2,б). Такие же различия имеют место, если при изготовлении люминофоров $\mathrm{CdS}-\mathrm{Ag}$ в атмосфере аргона для сушки последнего использовать концентрированную $\mathrm{H}_{2} \mathrm{SO}_{4}$ или ловушку с охлаждением аргона до $-72^{\circ}$. В последнем случае из аргона удаляется приблизительно в 20 раз больше влаги, чем при сушке концентрированной $\mathrm{H}_{2} \mathrm{SO}_{4}\left[{ }^{1}{ }^{1}\right]$. При этом повышается интенсивность свечения люминофора, а соотношение оранжевой и красной полос меняется в такой же степени, как и у люминофоров, изготовленных путем сухого перемешивания и введения активатора из раствора.

\section{Обсуждение результатов}

Происхождение и методы очистки исходного материала играют весьма важную роль в легировании сульфида кадмия. При обычных методах очистки, одинаковых концентрациях активатора и одинаковых условиях изготовления люминофоров получаются порой совсем разные полосы излучения. Вероятно, несмотря на очистку, из сульфида кадмия не устраняются примеси, которые играют активную роль в формировании центров свечения. То, что исходный порошок имеет только краевое излучение и что изменение стехиометрии не вызывает появления какого-либо другого свечения, не является, таким образом, признаком чистоты исходного материала, как это предполагалось ранее $[4,12]$. Исследованные нами люминофоры изготовлены из материалов, которые по их люминесцентным свойствам можно считать одинаково достаточно чистыми. Однако, как выяснилось, в действительности они имели разную степень чистоты.

Наши эксперименты показали, что самым чистым является сульфид кадмия, очищенный методом сублимации в высоком вакууме. Он не имеет никакого свечения ни при комнатной температуре, ни при температуре жидкого азота. В пользу того, что этот метод очистки дает действительно наиболее чистый сульфид кадмия, говорят следующие факты:

1) полученные люминофоры имеют одинаковые свойства,

2) изготовленные люминофоры интенсивнее, чем при использовании исходных материалов любой другой степени чистоты,

3) свечение не появляется без соактиватора; можно предположить, что в исходном материале содержится либо кислород, либо какой-то другой соактиватор, если свечение появляется уже при введении одного $\mathrm{Ag}_{2} \mathrm{~S}$ (или $\mathrm{Ag}$ ),

4) длины волн максимумов свечения при легировании серебром строго повторимы.

Результаты по легированию чистого сульфида кадмия показывают, что введение серебра вызывает появление излучения $\mathrm{CdS}$ в оранжевой

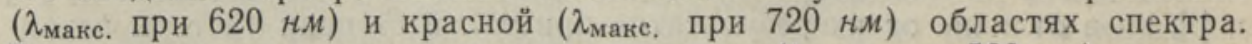

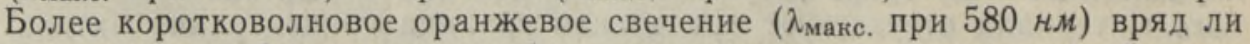
связано с серебром, хотя серебро при некоторых условиях способствует 
появлению его. Однако, как показывает эксперимент со смесью исходных материалов, это связано не с созданием новых центров люминесценции, а с устранением других (краевое свечение). Свечение при 580 нм может при большой яркости краевого свечения оставаться незаметным. Примеси, входящие в состав центров оранжевого свечения ( $\lambda_{\text {макс. при }}$ 580 нм), имеются, по-видимому, уже в исходных материалах, и серебро для создания этих центров не нужно.

Таким образом, главная причина несовпадения результатов разных авторов состоит, по-видимому, в использовании сульфида кадмия разной степени чистоты и разных методов его дополнительной очистки. Исходные материалы содержат неконтролируемые примеси, которые активно влияют на результаты легирования сульфида кадмия, и используемые обычно методы очистки недостаточны для освобождения от них. Наилучший метод очистки сульфида кадмия - пересублимация исходного материала в высоком вакууме. Получаемый в результате такой очистки сульфид кадмия не светится ни при комнатной температуре, ни при температуре жидкого азота.

Результаты, полученные с чистым сульфидом кадмия, показывают, что серебро в $\mathrm{CdS}$ не дает излучения без соактиватора. Соактиватором, по-видимому, может быть и кислород, так как при введении в $\mathrm{CdS}$ серебра в виде $\mathrm{AgNO}_{3}$ возникает излучение без дополнительных соактиваторов. В зависимости от соотношений концентраций серебра и соактиватора в люминофоре $\mathrm{CdS}-\mathrm{Ag}$ преобладает или оранжевая ( $\lambda_{\text {макс. }}$

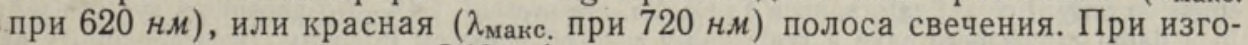
товлении люминофоров $\mathrm{CdS}-\mathrm{Ag}$ необходимо избегать влаги, так как она существенно снижает интенсивность свечения и может вызвать изменение соотношения интенсивностей полос свечения.

Авторы выражают благодарность А. Калдалу, А. Лепп и Л. Тулва за помощь при очистке и легировании $\mathrm{CdS}$.

\section{ЛИТЕ РА Т У Р А}

1. Kul p, B. A., Kelle y, R. H., J. Appl. Phys., 31, 1057 (1960).

2. Kul p, B. A., Phys. Rev., 125, 1865 (1962).

3. Власенко Н. А., Денисова 3. А., Витриковский Н. И., Павлен к о В. Ф., Опт. и спектр., 21, 446 (1966).

4. Г у р в и ч А. М., Исследование физико-химической природы сульфидных рентгенои фотолюминофоров. Автореф., М., 1968.

5. B rown, M. R., Cox, A. F. I., Sha nd, W. A., Willi a ms, J. M., J. of Luminescence, 3, 96 (1970).

6. Ермолович И. Б., Матвиевская Г. И., Пекарь Г. С., Шейнкман M. К., УФЖ, 18, 732 (1973).

7. Ермолович И. Б., М ат ви евская Г. И., Пек арь Г. С., Шейкм ан М. К., Проблемы физики соединений $\mathrm{A}^{\mathrm{II}} \mathrm{B}^{\mathrm{VI}}$, т. II. Вильнюс, 1972, с. 76.

8. К алдалу А. Е., Келле Х. И., К оппел Х. Д., Изв. АН ЭССР. Физ.мат., 23, 248 (1974).

9. Келле Х. И., Кир с Я. Я., Т улв а Л. Т., Тр. ИФА АН ЭССР, 41, 129 (1972),

10. Go o l, W. van, Philips Res. Repts, 13, 15 (1958).

11. Справочник химика, ч. I. М., 1963, с. 1059.

12. Klick, C. C., Schulman, J. H., Solid State Physics, Academic Press Inc. Publishers, N. Y., 5, 97 (1957).

Институт физики

Академии наук Эстонской ССР
Поступила в редакцию 28/V 1976 
Helgi KELLE, J. KIRS

\section{CdS-i EELNEVA PUHASTAMISE MOJU \\ CdS-Ag LUMINOFOORIDE SUNTEESILE}

Artiklis on esitatud uus CdS-i puhastamise meetod, mis seisneb pulbri ülesublimeerimises vaakuumis (kuni $10^{-5} \mathrm{~mm} \mathrm{Hg}$ ). Sellisel meetodil puhastatud CdS ei luminestseeru ei toatemperatuuril ega $77 \mathrm{~K}$ juures. Sellest lähteainest valmistatud $\mathrm{CdS}-\mathrm{Ag}$ luminofoorid moodustuvad ainult kaasaktivaatori manulusel. Niiskus nörgendab oluliselt nende kiirgust. Lahkuminekud erinevate autorite tulemustes CdS-i legeerimisel hõbedaga on seletatavad kasutatavate lähteainete erineva puhtusastmega.

Helgi KELLE, J. KIRS

\section{EFFECT OF PRELIMINARY PURIFICATION OF CdS ON THE SYNTHESIS OF CdS-Ag PHOSPHORS}

A new method of purification of CdS by sublimation in a vacuum of $10^{-5}$-Torr has been developed. CdS, purified in such a way, has no luminescence either at room temperature or at $77 \mathrm{~K}$. CdS-Ag phosphors prepared from this raw material exhibit luminescence emission only if co-activators, such as $\mathrm{Cl}, \mathrm{Ga}$, are present. $\mathrm{CdS}-\mathrm{Ag}$ phosphors synthesized in a damp atmosphere have a remarkably reduced emission intensity. Irreproducibility of the properties of CdS- $\mathrm{Ag}$ phosphors prepared by different investigators can be accounted for by the different purity of the raw materials used. 